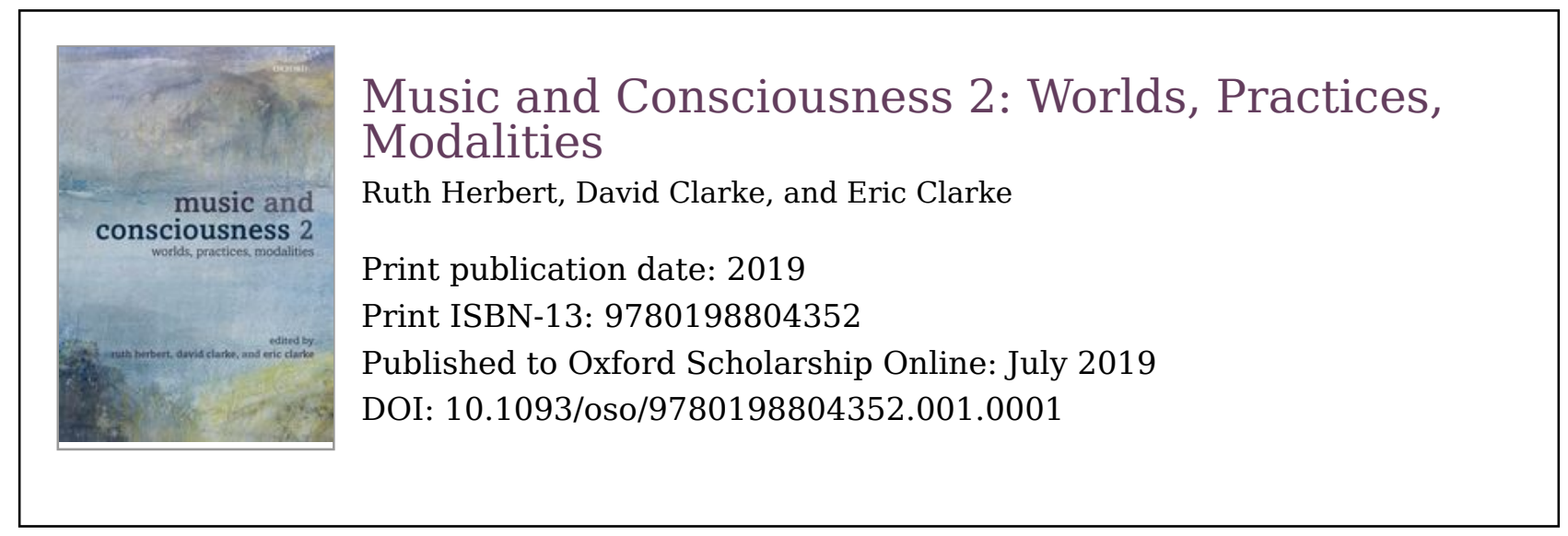

\title{
Music as affective scaffolding
}

Joel Krueger

DOI:10.1093/oso/9780198804352.003.0004

\begin{abstract}
Keywords
For 4E cognitive science, minds are embodied, embedded, enacted, and extended. Proponents observe that we regularly 'offload' our thinking onto body and world: we use gestures and calculators to augment mathematical reasoning, and smartphones and search engines as memory aids. This chapter argues that music is a 'beyond-the-head' resource that affords offloading. Via this offloading, music scaffolds access to new forms of thought, experience, and behaviour. The chapter focuses on music's capacity to scaffold emotional consciousness, including the self-regulative processes constitutive of emotional consciousness. In developing this idea, the chapter considers the 'material' and 'worldmaking' character of music, applying these considerations to two case studies: music as a tool for religious worship, and music as a weapon for torture.
\end{abstract}

Keywords: 4E cognition, consciousness, emotion, emotion regulation, musical world, materiality of music, music and worship, music and torture

\section{Introduction}

4E approaches in cognitive science see mind as embodied, embedded, enacted, and extended. They observe that we routinely 'offload' our thinking onto body and world. Tilting our head to make sense of a rotated image or text, for example-instead of rotating an internal representation-reduces informationprocessing demands (Risko and Gilbert 2016). Similarly, we use gesture to represent solutions to mathematical problems (Goldin-Meadow, Nusbaum et al. 2001), sketchpads to scaffold artistic creation (Loughlin 2012), models to better understand scientific theories (Toon 2015), and smartphones, search engines, and cultural institutions to support memory (Gallagher and Crisafi 2009). These 
'beyond-the-head' targets of our offloading generate ongoing feedback loops that transform our cognitive profiles in real time and, in so doing, help us negotiate complex cognitive tasks. From a $4 \mathrm{E}$ perspective, understanding how minds work requires looking beyond heads and taking into account the different ways bodily, social, and material resources scaffold access to new forms of thought and experience (Clark 2008; Menary 2010; Shapiro 2011).

$4 \mathrm{E}$ theorists have recently turned to music cognition: from work on music perception (Clarke 2005; Kersten 2014; Krueger 2009, 2011a; Leman and Maes 2015; Matyja and Schiavio 2013) and musical emotions (Cochrane 2008; Krueger 2014a, 2014b; Schiavio et al. 2016; van der Schyff and Schiavio 2017; Witek et al. 2014), to improvisation and music education (Elliott and Silverman 2015; Geeves and Sutton 2015; Schiavio and Høffding 2015). In this chapter, I continue this trend. I argue that music, like other tools and technologies, is a beyond-thehead resource that affords offloading and via this offloading, music can (at least potentially) scaffold access to new forms of thought, experience, and behaviour. I focus especially on music's capacity to scaffold emotional consciousness, including the self-regulative processes constitutive of emotional consciousnessalthough I will say some things about how music can scaffold other cognitive processes, too. In developing this idea, I consider two aspects of music that have been largely overlooked in the philosophical literature: its 'material' and 'worldmaking' character. I apply these considerations to two cases studies: music as a tool for religious worship, and music as a weapon for torture.

\section{(p.56) Music as material for worldmaking}

Philosophers often portray music, along with the practices by which we engage with it, as largely distinct from everyday life. For example, Peter Kivy argues that the liberating power of music comes from 'its complete freedom from connection with our workaday world and its problems' (Kivy 1997: 209). Alvin Goldman defends a similar view. He assumes ('without further comment') that the social dimension of live music, for instance, is 'not a primary value for most concert goers' before defending his central claim that music is more detached from the real world than other art forms, and that this detachment is ultimately the source of the great value we place on music and musical experience (Goldman 1992: 35).

While we might engage with music in this relatively 'worldless' manner-I can put on headphones, turn off the lights in my bedroom, and lose myself in a solitary musical experience-it does not follow that this is our default way of engaging with music. ${ }^{1}$ Moreover, the worldless picture of musical engagement that Kivy and Goldman endorse is not well-equipped to capture the situated character of our most common musical practices, many of which involve others -such as listening while worshipping, studying, exercising, or deliberately using music to enrich an individual or collective emotional experience. In these and many other cases, music is something we interact with and bring into use 
(Clarke 2005; Krueger 2011a, 2015a; Menin and Schiavio 2012; Rentfrow 2012). In other words, we encounter music as material-an 'aesthetic technology' (DeNora 2000) - that we put to work in actively driving experience and behaviour.

Consider portable listening technologies like MP3 players and smartphones, along with the streaming music services that flow through them (Bull 2000). These are portable and personalized technologies for on-demand 'selfcare' (Skånland 2013). We use them to craft transient, site-specific soundworlds specifically to regulate emotional consciousness, whether at work, play, or rest. And because we have these technologies with us constantly, musical interactions are no longer infrequent occurrences; they are never more than a touchscreen away. If I feel my energy flagging and need an affective boost to propel me through a strenuous workout, I can scroll through my MP3 player until I find just the right track, or simply issue a voice command telling my smartphone to play some upbeat music (Fritz et al. 2013). Similarly, if the energy begins to drop at a party, a well-chosen track can instantly revitalize the atmosphere and animate dancing and further conversation. Because music is materialized in an array of portable technologies, it is thoroughly interwoven into everyday activities-from reading and writing to cooking, exercising, shopping, socializing, worshipping, resting, and commuting.

So music is something we do things with, and one of things we routinely do with music is construct and organize space. In other words, we make musicallystructured (p.57) environments to inhabit, explore, and manipulate (Bull 2007). This 'worldmaking' dimension of music flows from its materiality. Because music is materialized in aesthetic technologies, we can use it to manipulate physical and social spaces-again, think of playing specific music to set the right atmosphere at a party, or in a waiting room, restaurant, or retail space-as well as to create individualized soundworlds nested within these spaces. For example, office workers in shared or open-plan office settings routinely use music to construct 'auditory bubbles' (Dibben and Haake 2013; Eriksson et al. 2017). These private soundworlds reclaim individual space, block out environmental distractions by creating a preferred auditory environment conducive to work, and provide resources to help manage attention, affect, and energy.

The spatial or worldmaking power of music also comes through in how we talk about music and musical experience. For example, when talking about pitch organization-a uniquely musical feature-we rely on spatial contrasts like 'up and down', 'high and low', 'small and large', and so on (Eitan and Timmers 2010; Morgan 1980). Spatial and movement metaphors are also central in descriptions of our strong emotional responses to music: 'sad music helps you enter your own true feelings' (Peltola and Saresma 2014: 298); 'suddenly I was in some inexplicable way drawn into the music. It felt as if I was somehow lifted up from my seat and sort of floated in the room ... The music crawled inside me; or was it 
me that crawled inside the music? In some way that was all that existed' (Gabrielsson 2011: 79-80).

These descriptions should be read as more than metaphors. They highlight the extent to which the experience of space is a constituent feature of musical consciousness (Krueger 2011b). The phenomenologist Maurice Merleau-Ponty was attuned to this spatial or worldmaking character of music, as when he wrote: 'a piece of music comes very close to being no more than a medley of sound sensations: from among these sounds we discern the appearance of a phrase and, as phrase follows phrase, a whole and, finally, as Proust puts it, a world' (2004: 99); and also:

In the concert hall, when I reopen my eyes, visible space seems narrow in relation to that other space where the music was unfolding just a moment ago, and even if I keep my eyes open during the performance of the piece, it seems to me that the music is not truly contained in this precise and shabby space. The music insinuates a new dimension across visible space where it unfurls just as, for persons suffering hallucinations, the clear space of perceived things is mysteriously doubled with a 'dark space' where other presences are possible. It brings a new dimension stealing through visible space, and in this it surges forward. (Merleau-Ponty 2002: 257-8)

A way of interpreting Merleau-Ponty's potentially cryptic remarks here is to see them as his attempt to distinguish two forms of spatial content intrinsic to musical consciousness-both of which are important for understanding music's worldmaking character and its ability to manipulate emotions, as we will see later. On the one hand, we hear music as an event located in the environment. This is to perceive music's locational spatial content-to hear music as coming from somewhere in 'visible space', as Merleau-Ponty puts it (e.g. the stereo in the next room, the tinny smartphone speaker three rows behind me on the bus, or the audio system of the car driving past my house). Locational spatial content specifies (p.58) music as an event situated in the environment, located in relation to listeners and other things and events. Because music bears locational spatial content-and is materialized in artefacts like MP3 players, speakers, and instruments-it can be selectively positioned in the world and used to alter its structure (recall the 'auditory bubble' example earlier).

But Merleau-Ponty also highlights a second form of spatial content intrinsic to musical consciousness particularly relevant to present concerns: the inner structural space of music. This inner space is a property that individuates music qua music in contrast to other sound events in the environment. For example, while we also tend to hear other sounds as bearing locational spatial content-I hear the hum of the fan by the window, the whine of the washing machine in the laundry room, or the laughter of children playing on the grass outside my office 
- music becomes present to consciousness in a different way. We hear it as also having a distinctive internal spatial complexity. It is perceived as a structurally organized soundworld that can be inhabited, experientially, in a way many other sounds cannot. ${ }^{2}$ What this means is that we hear musical elements like tones, melodies, rhythmic progressions, and textures as meaningfully arranged to hang together in a particular sort of way. This 'hanging together' establishes a musical event's distinctively musical profile, its coherence as a musical event. And it renders music meaningful insofar as it immediately shows up for us not as random noise but as a phenomenologically rich-sounding environment intentionally crafted to invite different forms of perceptual and behavioural engagement (Clarke 2013; Reybrouck 2015). Phenomenologically, the dynamic interplay between locational and structural musical space is, I suggest, a central reason why music becomes present to consciousness with its distinctive character and meaning. ${ }^{3}$

In sum, our experience of music qua music involves the perception of musical space, a musical world. Moreover, because music is mediated materially (for example, by aesthetic technologies), we can do things with it-including manipulating the spaces of our environments and, simultaneously, ourselves. By virtue of its materiality, music integrates with (p.59) and dynamically reorganizes physical and social spaces, opening up new possibilities for musically scaffolded experience and action.

Offloading and musical worlds Music's material and worldmaking character is what enables it to function as beyond-the-head scaffolding that affords offloading. As will become clear, sometimes this offloading is voluntary, and sometimes it is not. Two case studies will help clarify this idea: music as a tool for religious worship, and music as a weapon for torture.

\section{Music and worship}

Music has long been central to religious practice (Wynn 2004). When we enter a church, mosque, or temple, we enter not just a religious but also a musical space, in which we may find soundworlds fashioned specifically to demarcate that space as sacred and to scaffold religious emotions, beliefs, memories, and behaviour.

There is a well-established connection between music and emotion regulation. The latter refers to processes by which we determine which emotions we have, when and how long we have them, and how these emotions are experienced and expressed (Gross 1999). Emotions are complex phenomena comprised of multiple integrated dimensions: an appraisal dimension, for instance, as well as an agentive or action-readiness dimension, a physiological dimension, and an expressive dimension (Parkinson 1995). But emotions also have a regulatory dimension, and if, as some argue (e.g. Frijda 1986; Tomkins 1984), emotion- 
regulative and emotion-generative processes are inextricable, processes of emotion regulation are partially constitutive of emotional consciousness. In other words, how an emotion feels reflects the manner by which it is regulated (Krueger 2015b).

Traditionally, emotion regulation has been seen as a process that occurs almost entirely inside people's heads (e.g. Gross 2015). But this individualistic perspective overlooks emergent qualities of emotion regulation and experience that are scaffolded by an individual's ongoing engagement with features of their environment (Koole and Veenstra 2015), including their musical environment (van der Schyff and Schiavio 2017). As already discussed, we use music throughout our lives and in many different contexts, including religious worship, to regulate our emotions (Saarikallio 2011). We do this because music is an aesthetic technology especially well-suited for this task. Its dynamic and temporal nature, along with its deep bodily impact on listeners-the fact that musicking enacts continuous feedback loops of musical 're-soundings' (Nancy 2007), from vibrations in our bones and muscles to complex patterns of neurophysiological and behavioural entrainment-means that we are quite literally bodily and affectively captured by the musical worlds we construct and inhabit. These worlds pull emotional responses out of us and regulate the character of their unfolding.

This picture is supported by a great deal of empirical work. For example, neuroimaging studies have found that musical responses utilize many of the same brain regions involved in generating, detecting, maintaining, and regulating emotions (Blood et al. (p.60) 1999; Koelsch 2014; Overy and MolnarSzakacs 2009). But music affects more than just our neurons. Musickingwhether listening alone with headphones, during a religious service, or dancing with thousands of people at a festival-is a richly cross-modal and whole-body experience involving embodied expressions (facial expressions, gestures, and other bodily movements) central to emotional consciousness (Laird 2007; Maiese 2011). Exploring the details of these processes would take us too far afield (see Krueger 2014a for an in-depth discussion). For now, we can simply note that even when we are supposedly 'passively' listening, we are still interactively engaged with the music at multiple levels of our embodiment: our motor system is involved in processing musical rhythms (Chen et al. 2008; Grahn and Brett 2007); we make spontaneous facial expressions when listening to expressive music, including non-vocal music (Chan et al. 2013; Lundqvist et al. 2009; Witvliet and Vrana 1996); and we spontaneously entrain our movements, gestures, and facial expressions (from subtle head bobs and toe taps to fullblown ecstatic dancing) with musical elements like rhythm and melody, and in so doing become intimately 'coupled' with the music and the things that are happening in it (Iyer 2002; Janata et al. 2012; Witek et al. 2014). 
In this way, then, the musical worlds we inhabit elicit and directly modulate a cascade of emotion-specific processes at neurophysiological, behavioural, and experiential levels. The important point here is this: via iterative cycles of motor entrainment and synchronization unfolding in response to musical features, musical worlds pull emotions out of us and regulate their dynamics in real time as they unfold over short- and long-term listening episodes (Elvers 2016; Janata et al. 2012; Windsor and de Bézenac 2012). Music thus functions as environmental scaffolding, that is, as part of our extended (beyond-the-head) emotion-regulatory system. The music we play, or that is played around us (e.g. in spaces of worship), becomes part of a listener-environment feedback loop that drives, structures, and regulates the character and development of our emotional consciousness. This is, I suggest, a case of musically scaffolded emotional offloading. We let music take over self-regulatory dynamics that would normally fall within the scope of our own internal capacities and, via this offloading, let it do some of the emotional work for us (Krueger 2014a, 2014b).

To make this idea more concrete-and to return to music and worship-consider music at a religious funeral. The musical soundworld of a funeral has a number of functions (Clarke et al. 2010: 1-8). Solo organ music before the service masks environmental sounds and demarcates the physical space of the funeral as different from the 'everyday', provides aural privacy for attendees, and guides attention and focus as the service begins. A funeral's soundworld is also selected to scaffold and regulate the experience and expression of appropriate emotions. Loud up-tempo pop music would normally be considered inappropriate, unless specifically requested by the deceased. So, slower reverent musical worksChristian hymns like 'Abide with Me', for example, or classical pieces like Elgar's Enigma Variations, Pachelbel's Canon in D Major, or Verdi's Requiem-are chosen for their capacity to establish an affective atmosphere, gently nudging participants towards quiet grief and introspective remembrance.

(p.61) However, not all funerals are sombre affairs. Within the Southern Baptist tradition in the United States, African American funerals often begin with mournful hymns and prayer, but they soon transition into something very different: joyful celebrations of the deceased's reunion with Christ, complete with shouting, singing, and dancing that spills out of the pews and into the aisles. These emotional displays are scaffolded by up-tempo praise hymns. The musical soundworld organizes and guides this transition, actively driving participants' emotions and behaviours, both individually and collectively, as they pass through various phases of this process. Via the entrainment responses discussed previously, rhythmic and tonal properties of the music pull embodied responses directly connected with positive and uplifting emotions out of attendees and regulate how these emotions unfold over the course of this episode. This is a full-bodied engagement with musical scaffolding. As Clarke and colleagues note, '[t]he very act of singing, involving deliberately deep breathing, the increased muscle tone associated with standing up, and the 
concentration required to follow the words and music, also bring together physiological and psychological phenomena commonly used to help people cope with, and overcome, strong negative emotions' (2010: 6).

Other forms of musical offloading can be found within religious contexts. For example, music scaffolds social cognitive processes, such as social bonding, by synchronizing the moods and emotions of a large number of people-again, via the entrainment processes discussed previously (Clarke et al. 2015; Launay 2015; Reddish et al. 2013). These musically scaffolded moods and emotions in turn regulate the large-scale synchronization of joint action and behaviour. This is a central ritual function of music. Rituals are patterns of organized behaviour that follow a prescribed form. They can unfold at multiple timescales, from moments to years or a lifetime, and can involve a few people or many. Music often plays a crucial role in driving the different practices and behaviours constitutive of religious rituals. Musical qualities like rhythm, melody, and pulse order the temporal sequence of a service and organize behavioural coordination between participants. They do this by providing external time-keeping cues, enabling groups to move and act in time, as one (Clarke et al. 2010: 2-3). For example, in a Christian service, organ or choral music signals when to sit, stand, kneel, pray, or greet one's fellow worshippers; musical cues also signal the start of the gospel reading, tell participants when to approach the front of the church for communion, and even determine what sort of actions are appropriate during a particular phase of the service (e.g. when walking back to one's pew after communion versus post-worship mingling).

In this way, music encodes action scripts constitutive of a given ritual or service of worship. Instead of participants having to remember each and every movement or practice, they can offload this responsibility onto the music by letting it take over and govern their behaviour. Music thus materializes ritualistic time. Musical dynamics are external representations indicating that things are happening right here, right now; and these dynamics tell listeners what to do and when to do it (Rouget 1985).

Canonical music in this way preserves ritualistic practices and action scripts over many generations, scaffolding not just individual and collective, but also intergenerational, (p.62) memory. Songs, hymns, chants, and sung prayers continually remind worshippers of their religious duties and actions; and as we have seen, they elicit and regulate appropriate moods or emotional responses. But they also preserve and communicate the stories, myths, legends, beliefs, and practices of a religious tradition across multiple generations. Rhythms and melodies chunk words and phrases, identify line lengths and stress patterns, and help listeners focus on and recall important words of a text, such as those found in a religious scripture or creed (Wallace 1994). In sum, in addition to its impact on emotional consciousness, music is a memory technology that scaffolds 
processes of learning, retrieving, remembering, and reconstructing the rituals and texts constitutive of religious life.

\section{Music and torture}

Inhabiting religious and musical spaces is generally a voluntary and uplifting affair. Worshippers create and inhabit these environments in order to enrich their own musically scaffolded experiences and share them with others. But not all instances of musical offloading have these positive qualities. Music weaponized as an instrument of torture is one such case-and it reaffirms music's potency as affective scaffolding.

Consider prisons. Prisons are complex soundworlds, and very noisy environments. The jangling of keys carried by prison guards, the banging of heavy prison doors, the shouting and screaming of guards and unruly prisoners, the barking of patrol dogs, and the loud music blaring from radios all contribute to an unpleasant soundworld amplified by the austere space of the typical prison environment (Archer 2002; Carlton 2007). This takes its toll: long-term exposure to prison noise has been linked to deafness (Grossman et al. 1996), and has led some to argue that the intensity and unpredictability of prison noise, along with prisoners' relative powerlessness to do much about it, is another form of punishment and suppression of their agency (Cusick 2013; Rice 2016).

However, prisoners can, at times, exert their acoustical agency by creating personalized soundworlds with music. Recently, some prisons have given prisoners MP3 players as a reward for good behaviour (Kirkpatrick 2013). They quickly become prisoners' most prized commodity-used to create 'auditory bubbles', as in office environments, to reclaim individual space, bring order to an unpredictable sonic environment, and regulate affect. But prisoners also weaponize these MP3 players and the soundworlds they create. Loud rap music played through portable speakers attached to these MP3 players can be a hostile gesture, a means of demarcating territory through sound and deliberately inflicting stress, sleep deprivation, and negative affect on others (Rice 2016). The playing of loud music is the most common cause of fights among inmates (Archer 2002).

Music can be weaponized in an even more damaging way, however. It is well established that the United States military uses music as an element of 'harsh interrogation' in the so-called 'global war on terror' (Bayoumi 2005; Cusick 2013; Peisner 2006). High-value detainees are routinely subjected to punishingly loud music for hours or days at a time via loudspeakers in individual cells and interrogation rooms or positioned just outside communal prison blocks-with prisoners often standing or kneeling in an uncomfortable (p.63) posture. Media accounts tend to downplay the severity of these techniques, focusing not on the character of the experience but rather on the amusing juxtaposition of artists found in the playlists (e.g. Barry Manilow, Slayer, Eminem, the theme song from 
the American children's programme Barney the Dinosaur). But music is a powerful technology for torture. It is telling that victims find the predictability of physical violence preferable to the unpredictability of musical torture (Grüny 2012).

To better understand the phenomenology of musical torture and how (involuntary) offloading is central to the experience, two points are worth noting. First, as Grüny (2012) observes, sounds-particularly musical sounds-seem to penetrate consciousness in a qualitatively deeper way than input from other perceptual modalities. As he puts it, 'the audible is organized around degrees of intensity, and it seems to imply a rather different relation between activity and passivity' than we find in other experiences (Grüny 2012: 209). If I am in a brightly lit room or outside in direct sunlight, say, I can move to shade or cover my eyes and enjoy some relief; similarly, I can plug my nose and escape an unpleasant odour or shift my body away from an irritating tactile sensation. While we do, of course, have some autonomy over the intensity of our auditory experiences, we also seem uniquely vulnerable to sounds. This is because we resonate with sounds-particularly music-down to our bones (Cusick 2008). Music played at high volume bombards listeners' bodies with relentless acoustical energy, and, as we have seen, elicits an array of neurophysiological and behavioural entrainment responses over which they have little control and which are directly linked to emotion regulation. This aspect of music's materiality makes it an especially powerful tool for control and domination. ${ }^{4}$

Second, and relatedly, we often enter and become deeply affected by shared musical worlds not of our making. Focusing on MP3 players as technologies of self-care might lead us to think of musical worlds as primarily solitary environments. But as the discussion of music and worship has highlighted, musical worlds are often collaboratively constructed environments; and musical worlds created by others often co-opt our attention and emotions, and regulate our behaviour in deep and subtle ways-even if we are not aware that it is happening. For example, background music while shopping influences (p.64) what consumers buy and how much they are willing to pay for their purchases (Areni and Kim 1991; North et al. 2016; Turley and Milliman 2000).

To return to music and torture: these cases of weaponized musical worlds are powerful examples of what Jan Slaby calls 'affective mind invasion' (Slaby 2016). Affective mind invasion occurs when an individual's affective and emotional dispositions fall in line with the interaction routines of their local subcultures. The latter refers to things like corporate workplaces, social web-based groups, academia, the world of sports, or police and military culture. Over time, individuals within these domains adopt idiosyncratic 'affective styles': ways of speaking, gesturing, and moving, patterns of interpersonal interaction, emotional experience, and expression, and such like, that are normative in the domain in question (Colombetti and Krueger 2015). Individuals are affectively 
'invaded' to the extent that these styles can regulate thought and behaviour without their full awareness or consent.

Musical torture is a particularly brutal case of affective mind invasion. Part of its brutality comes from the fact that aspects of one's bodily-affective style-and emotional consciousness more generally-are not so much reconfigured as they are dismantled and destroyed. Prisoners are drawn up into (scaffolded by) a hostile musically extended self-regulatory system without their consent. Their subjectivity, their ability to self-regulate thought and emotion, is co-opted and absorbed by a weaponized musical world not of their making.

Reports suggest that much of prisoners' disorientation comes from the fact that music played so loudly and repeatedly is drained of its aesthetic qualities and instead becomes an all-consuming violent sound. The individual can no longer selectively attend to or pleasurably entrain with qualities like melody or rhythm. Instead, their agency is diminished and they are completely subsumed by the music: 'after a while, you don't hear the lyrics, all you hear is heavy, heavy banging ... you can't concentrate on the drums, or what the person's saying, all you hear is just loud shouting, loud banging, the metal clashing against metal ... It doesn't sound like music at all' (Cusick 2008: 3).

Another individual describes the isolating character of the experience-the removal of access to external cues, such as voices and other sounds, that normally situate us in a physical and social world: 'Nothing focused in terms of, like, let me think now of, for example, a topic or story. Nothing comes to your head: it's just that the experience you're going through is so intense ... that it takes you away from everything else, everything else besides it' (Cusick 2013: 287). In contrast to the timekeeping function of music in religious worship, music in the context of torture is used specifically to disrupt the subject's experience of time and remove connections with the physical and social world. Even when the music eventually stops, the inmate can report feeling like a cat 'just turning in a spot, saying "What's going on? What's going on?" ' (Cusick 2013: 287)

Other prisoners affirm the materiality of music as an active force in the world: 'You feel like your body is being bombarded with something ... It's like you're being hit with a hammer, din din din din. When it stops, it's like a beating has stopped' (Cusick 2013: 288). When played at a high volume for extended periods, music's acoustical energy becomes, (p.65) Cusick tells us, 'a vibrating presence of power that can deliver a miraculously ubiquitous battering to the sympathetically vibrating bones and skin of a man, beating him from within and without, while leaving no marks' (2013: 288).

This process of affective mind invasion destroys the individual's sense of interiority and exteriority, private and public. By forcing the individual to 
unwillingly offload self-regulatory processes onto a hostile musical world not of their making, the music removes individual agency and consent. Prisoners are, accordingly, drawn up into a musically extended system crafted not to augment and enhance but rather to dismantle and destroy.

\section{Conclusion}

Both my case studies-despite their many differences-highlight the deep way in which music can take over and regulate various processes responsible for the development, maintenance, and control of our embodied subjectivity. More specifically, both show how self-regulative processes responsible for generating and maintaining emotional consciousness can be offloaded onto the musical worlds we inhabit. Sometimes, as in the case of music and worship, this process happens voluntarily, within musical worlds of our own making; in other cases, however, this offloading is involuntary, and involves musical worlds others create for us-and even use against us. Music and torture provides a powerful example of the latter. Two qualities of music-its material and worldmaking character, often overlooked by philosophers of music-are what enable it to function as affective scaffolding in this way.

There are several points in conclusion. First, philosophers of music, I suggest, ought to take their lead from music sociologists and psychologists and pay more attention to the situated nature of our everyday musical practices-the fact that music is something we regularly do things with. One of the main things we do with music is actively use it to manipulate our emotional consciousness. This enactive way of thinking about music and emotions has only recently found a prominent place within philosophical debates. But this is where $4 \mathrm{E}$ cognition can help. Broadening the scope of inquiry to include not just experiences such as attending a symphony orchestra but also musical practices embedded in everyday contexts of work, play, learning, and rest will benefit from further engagement with $4 \mathrm{E}$ cognition, which is committed to understanding how the dynamics of cognition and emotion arise within these contexts. A particularly fruitful avenue of future research here might be the role of music in scaffolding affective processes involved in pedagogy and learning (Elliott and Silverman 2015). For example, there is suggestive evidence that musical engagementsboth scripted and spontaneous music making, as well as music listening and dancing - can play a crucial role in deepening young learners' selfunderstanding, empathy, and sensitivity to their sociocultural milieu (van der Schyff et al. 2016).

Second, this picture of music as affective scaffolding seems to lend support to some of the more radical strands of $4 \mathrm{E}$ cognition. These strands include those who see a wide (p.66) variety of psychological states and processes-including consciousness and emotions-as partially constituted by beyond-the-head factors. Traditionally, some prominent $4 \mathrm{E}$ proponents sympathetic to the idea that cognitive processes such as believing and remembering can extend beyond 
the head via the input of environmental resources (e.g. notebooks, smartphones, cultural institutions and practices) stop short of endorsing the idea that conscious states might be similarly extended (Clark 2009; cf. Ward 2012). However, this reluctance is starting to change (Rowlands 2015; Vold 2015) particularly in the realm of emotions (Carter et al. 2016; Colombetti and Roberts 2015; Krueger and Szanto 2016; Roberts 2015; Slaby 2014). Given the ubiquity and variety of our musical practices, as well as the tight connection between music and emotions, music ought to be a core focus of these externalist trends in the philosophy of emotions. Musical worlds shape emotional minds.

Understanding the latter requires looking beyond the head, into the soundtracks of everyday life.

Acknowledgements

I am very grateful to Eric Clarke and David Clarke for their thorough comments on earlier versions of this chapter. Their feedback greatly improved my thinking about these issues. My thanks also to audiences in Berlin, Irvine, and Brussels for helpful feedback on talks related to this material. Substantial parts of this chapter overlap with the talk 'Musical Worlds and Extended Mind', published in Proceedings of A Body of Knowledge-Embodied Cognition and the Arts conference CTSA UCI, 8-10 December 2016.

\section{References}

Bibliography references:

Archer, J. (2002). A Prison Diary. London: Macmillan.

Areni, C.S. and Kim, D. (1991). The influence of background music on shopping behavior: Classical versus top-forty music in a wine store. Advances in Consumer Research. Association for Consumer Research, 20, 336-40.

Bayoumi, M. (2005). Disco inferno. The Nation, 26 December 2005. Available at: https://www.thenation.com/article/disco-inferno/ (accessed 16 October 2016).

Blood, A.J., Zatorre, R.J., Bermudez, P., and Evans, A.C. (1999). Emotional responses to pleasant and unpleasant music correlate with activity in paralimbic brain regions. Nature Neuroscience, 2(4), 382-7.

Bull, M. (2000). Sounding Out the City: Personal Stereos and the Management of Everyday Life. Oxford: Berg.

Bull, M. (2007). Sound Moves: iPod Culture and Urban Experience. London: Routledge.

Carlton, B. (2007). Imprisoning Resistance: Life and Death in an Australian Supermax. Sydney: Institute of Criminology Press. 
Carter, J.A., Gordon, E.C., and Palermos, S.O. (2016). Extended emotion. Philosophical Psychology, 29(2), 198-217.

Chan, L.P., Livingstone, S.R., and Russo, F.A. (2013). Facial mimicry in response to song. Music Perception, 30(4), 361-7.

Chen, J.L., Penhune, V.B., and Zatorre, R.J. (2008). Listening to musical rhythms recruits motor regions of the brain. Cerebral Cortex, 18(12), 2844-54.

(p.67) Clark, A. (2008). Supersizing the Mind: Embodiment, Action, and Cognitive Extension. Oxford: Oxford University Press.

Clark, A. (2009). Spreading the joy? Why the machinery of consciousness is (probably) still in the head. Mind, 118(472), 963-93.

Clarke, E.F. (2005). Ways of Listening: An Ecological Approach to the Perception of Musical Meaning. New York, NY: Oxford University Press.

Clarke, E.F. (2013). Music, space, and subjectivity. In G. Born (ed.), Music, Sound, and Space: Transformations of Public and Private Experience (pp. 90110). Cambridge: Cambridge University Press.

Clarke, E., DeNora, T., and Vuoskoski, J. (2015). Music, empathy and cultural understanding. Physics of Life Reviews, 15, 61-88.

Clarke, E.F., Dibben, N., and Pitts, S.E. (eds.) (2010). Music and Mind in Everyday Life. Oxford: Oxford University Press.

Cochrane, T. (2008). Expression and extended cognition. The Journal of Aesthetics and Art Criticism, 66(4), 329-40.

Colombetti, G. and Krueger, J. (2015). Scaffoldings of the affective mind. Philosophical Psychology, 28(8), 1157-76.

Colombetti, G. and Roberts, T. (2015). Extending the extended mind: The case for extended affectivity. Philosophical Studies, 172(5), 1243-63.

Cupchik, G.C., Phillips, K., and Hill, D.S. (2001). Shared processes in spatial rotation and musical permutation. Brain and Cognition, 46(3), 373-82.

Cusick, S.G. (2008). Musicology, torture, repair. Radical Musicology, 3, 1-9. Available at: http://www.radical-musicology.org.uk/2008/Cusick.htm (accessed 7 January 2019).

Cusick, S.G. (2013). Towards an acoustemology of detention in the 'global war on terror'. In G. Born (ed.), Music, Sound, and Space: Transformations of Public and Private Experience (pp. 275-91). Cambridge: Cambridge University Press. 
DeNora, T. (2000). Music in Everyday Life. Cambridge: Cambridge University Press.

Dibben, N. and Haake, A.B. (2013). Music and the construction of space in office-based work settings. In G. Born (ed.), Music, Sound and Space: Transformations of Public and Private Experience (pp. 151-68). Cambridge: Cambridge University Press.

Douglas, K.M. and Bilkey, D.K. (2007). Amusia is associated with deficits in spatial processing. Nature Neuroscience, 10(7), 915-21.

Eitan, Z. and Timmers, R. (2010). Beethoven's last piano sonata and those who follow crocodiles: Cross-domain mappings of auditory pitch in a musical context. Cognition, 114(3), 405-22.

Elliott, D.J. and Silverman, M. (2015). Music Matters: A Philosophy of Music Education (2nd edn). New York, NY: Oxford University Press.

Elvers, P. (2016). Songs for the ego: Theorizing musical self-enhancement. Frontiers in Psychology, 7(2), 1-11.

Eriksson, M.L., Atienza, R., and Pareto, L. (2017). The sound bubble: A contextsensitive space in the space. Organised Sound, 22(1), 130-9.

Frijda, N.H. (1986). The Emotions. Cambridge: Cambridge University Press.

Fritz, T.H., Hardikar, S., Demoucron, M., Niessen, M., Demey, M., Giot, O., Li, Y., Haynes, J.D., Villringer, A., and Leman, M. (2013). Musical agency reduces perceived exertion during strenuous physical performance. Proceedings of the National Academy of Sciences of the United States of America, 110(44), 177849.

Gabrielsson, A. (2011). Strong Experiences with Music: Music Is Much More Than Just Music, trans. R. Bradbury. Oxford: Oxford University Press.

(p.68) Gallagher, S. and Crisafi, A. (2009). Mental institutions. Topoi, 28(1), 4551.

Geeves, A. and Sutton, J. (2015). Embodied cognition, perception, and performance in music. Empirical Musicology Review, 9(3-4), 247-53.

Goldin-Meadow, S., Nusbaum, H., Kelly, S.D., and Wagner, S. (2001). Explaining math: Gesturing lightens the load. Psychological Science, 12(6), 516-22.

Goldman, A. (1992). The value of music. The Journal of Aesthetics and Art Criticism, 50(1), 35-44. 
Grahn, J.A., and Brett, M. (2007). Rhythm and beat perception in motor areas of the brain. Journal of Cognitive Neuroscience, 19(5), 893-906.

Gross, J.J. (1999). Emotion regulation: Past, present, future. Cognition and Emotion, 13(5), 551-73.

Gross, J.J. (2015). Emotion regulation: Current status and future prospects. Psychological Inquiry, 26(1), 1-26.

Grossman, T.W., Kerr, H.D., and Byrd, J.C. (1996). Hearing loss in former prisoners of war of the Japanese. Journal of the American Geriatrics Society, 44(9), 1089-92.

Grüny, C. (2012). The language of feeling made into a weapon: Music as an instrument of torture. In J.A. Carlson and E. Weber (eds.), Speaking about Torture (pp. 205-17). New York, NY: Fordham University Press.

Herz, R.S., Eliassen, J., Beland, S., and Souza, T. (2004). Neuroimaging evidence for the emotional potency of odor-evoked memory. Neuropsychologia, 42(3), 371-8.

Iyer, V. (2002). Embodied mind, situated cognition, and expressive microtiming in African-American music. Music Perception, 19(3), 387-414.

Janata, P., Tomic, S.T., and Haberman, J.M. (2012). Sensorimotor coupling in music and the psychology of the groove. Journal of Experimental Psychology. General, 141(1), 54-75.

Kersten, L. (2014). Music and cognitive extension. Empirical Musicology Review, 9(3-4), 193-202.

Kirkpatrick, B. (2013). Regulating the carceral soundscape: Media policy in prison. Sounding Out!, 3 June 2013. Available at: https://soundstudiesblog.com/ 2013/06/03/regulating-the-carceral-soundscape-media-policy-in-prison/ (accessed 29 September 2016).

Kivy, P. (1997). Philosophies of Arts: An Essay in Differences. Cambridge: Cambridge University Press.

Koelsch, S. (2014). Brain correlates of music-evoked emotions. Nature Reviews. Neuroscience, 15(3), 170-80.

Koole, S.L. and Veenstra, L. (2015). Does emotion regulation occur only inside people's heads? Toward a situated cognition analysis of emotion-regulatory dynamics. Psychological Inquiry, 26(1), 61-8.

Krueger, J. (2009). Enacting musical experience. Journal of Consciousness Studies, 16(2-3), 98-123. 
Krueger, J. (2011a). Doing things with music. Phenomenology and the Cognitive Sciences, 10(1), 1-22.

Krueger, J. (2011b). Enacting musical content. In R. Manzotti (ed.), Situated Aesthetics: Art Beyond the Skin (pp. 63-85). Exeter: Imprint Academic.

Krueger, J. (2014a). Affordances and the musically extended mind. Frontiers in Psychology, 4(1003), 1-13.

Krueger, J. (2014b). Musical manipulations and the emotionally extended mind. Empirical Musicology Review, 9(3-4), 208-12.

Krueger, J. (2015a). Musicing, materiality, and the emotional niche. Action, Criticism, and Theory for Music Education, 14(3), 43-62.

Krueger, J. (2015b). The affective 'we': Self-regulation and shared emotions. In T. Szanto and D. Moran (eds.), Phenomenology of Sociality: Discovering the We (pp. 263-80). London: Routledge.

Krueger, J. and Szanto, T. (2016). Extended emotions. Philosophy Compass, 11(12), 863-78.

Laird, J.D. (2007). Feelings: The Perception of Self. Oxford: Oxford University Press.

Launay, J. (2015). Music as a technology for social bonding: Comment on 'Music, empathy, and cultural understanding' by E. Clarke et al. Physics of Life Reviews, 15, 94-5.

(p.69) Leman, M. and Maes, P.-J. (2015). The role of embodiment in the perception of music. Empirical Musicology Review, 9(3-4), 236-46.

Loughlin, V. (2012). Sketch this: Extended mind and consciousness extension. Phenomenology and the Cognitive Sciences, 12(1), 41-50.

Lundqvist, L.-O., Carlsson, F., Hilmersson, P., and Juslin, P.N. (2009). Emotional responses to music: Experience, expression, and physiology. Psychology of Music, 37(1), 61-90.

Maiese, M. (2011). Embodiment, Emotion, and Cognition. New York, NY: Palgrave Macmillan.

Matyja, J.R. and Schiavio, A. (2013). Enactive music cognition: Background and research themes. Constructivist Foundations, 8(3), 351-7.

McDonald, C. and Stewart, L. (2008). Uses and functions of music in congenital amusia. Music Perception, 25(4), 345-55. 
Menary, R. (ed.) (2010). The Extended Mind. Cambridge, MA: Bradford Books.

Menin, D. and Schiavio, A. (2012). Rethinking musical affordances. Avant, 3(2), 201-15.

Merleau-Ponty, M. (2002). Phenomenology of Perception, trans. C. Smith. New York, NY: Routledge.

Merleau-Ponty, M. (2004). The World of Perception. London: Routledge.

Morgan, R.P. (1980). Musical time/musical space. Critical Inquiry, 6(3), 527-38.

Nancy, J.-L. (2007). Listening, trans. C. Mandell. New York, NY: Fordham University Press.

North, A.C., Sheridan, L.P., and Areni, C.S. (2016). Music congruity effects on product memory, perception, and choice. Journal of Retailing, 92(1), 83-95.

Overy, K. and Molnar-Szakacs, I. (2009). Being together in time: Musical experience and the mirror neuron system. Music Perception, 26(5), 489-504.

Parkinson, B. (1995). Ideas and Realities of Emotion. New York, NY: Routledge.

Peisner, D. (2006). Music as torture: War is loud. Spin, 92. Available at: http:// www.spin.com/2006/11/music-torture-war-loud/ (accessed 16 October 2016).

Peltola, H.-R. and Saresma, T. (2014). Spatial and bodily metaphors in narrating the experience of listening to sad music. Musicae Scientiae, 18(3), 292-306.

Reddish, P., Fischer, R., and Bulbulia, J. (2013). Let's dance together: Synchrony, shared intentionality and cooperation. PLoS One, 8(8), e71182.

Rentfrow, P.J. (2012). The role of music in everyday life: Current directions in the social psychology of music. Social and Personality Psychology Compass, 6(5), 402-16.

Reybrouck, M. (2015). Music as environment: An ecological and biosemiotic approach. Behavioral Sciences, 5(1), 1-26.

Rice, T. (2016). Sounds inside: Prison, prisoners and acoustical agency. Sound Studies, 2(1), 6-20.

Risko, E.F. and Gilbert, S.J. (2016). Cognitive offloading. Trends in Cognitive Sciences, 20(9), 676-88.

Roberts, T. (2015). Extending emotional consciousness. Journal of Consciousness Studies, 22(3-4), 108-28. 
Rouget, G. (1985). Music and Trance: A Theory of the Relation between Music and Possession. Chicago, IL: University of Chicago Press.

Rowlands, M. (2015). Consciousness unbound. Journal of Consciousness Studies, 22(3-4), 34-51.

Saarikallio, S. (2011). Music as emotional self-regulation throughout adulthood. Psychology of Music, 39(3), 307-27.

Sacks, O. (2007). Musicophilia: Tales of Music and the Brain. London: Picador.

Saive, A.-L., Royet, J.-P., and Plailly, J. (2014). A review on the neural bases of episodic odor memory: From laboratory-based to autobiographical approaches. Frontiers in Behavioral Neuroscience, 8(240), 1-13.

Särkämö, T., Tervaniemi, M., Soinila, S., Autti, T., Silvennoinen, H.M., Laine, M., and Hietanen, M. (2009). Cognitive deficits associated with acquired amusia after stroke: A neuropsychological follow-up study. Neuropsychologia, 47(12), 2642-51.

(p.70) Schiavio, A. and Høffding, S. (2015). Playing together without communicating? A pre-reflective and enactive account of joint musical performance. Musicae Scientiae, 19(4), 366-88.

Schiavio, A., van der Schyff, D., Cespedes-Guevara, J., and Reybrouck, M. (2016). Enacting musical emotions. Sense-making, dynamic systems, and the embodied mind. Phenomenology and the Cognitive Sciences, 16(5), 785-809. Available at: https://ezproxy-prd.bodleian.ox.ac.uk:4563/10.1007/s11097-016-9477-8.

Shapiro, L.A. (2011). Embodied Cognition. New York, NY: Routledge.

Skånland, M.S. (2013). Everyday music listening and affect regulation: The role of MP3 players. International Journal of Qualitative Studies on Health and WellBeing, 8(1), 20595.

Slaby, J. (2014). Emotions and the extended mind. In M. Salmela and C. Von Scheve (eds.), Collective Emotions (pp. 32-46). Oxford: Oxford University Press.

Slaby, J. (2016). Mind invasion: Situated affectivity and the corporate life hack. Frontiers in Psychology, 7(266), 1-13.

Tillmann, B., Jolicœur, P., Ishihara, M., Gosselin, N., Bertrand, O., Rossetti, Y., and Peretz, I. (2010). The amusic brain: Lost in music, but not in space. PLoS One, 5(4), e10173.

Tomkins, S.S. (1984). Affect theory. In P. Ekman (ed.), Emotion in the Human Face (2nd edn) (pp. 353-95). Cambridge: Cambridge University Press. 
Toon, A. (2015). Where is the understanding? Synthese, 192(12), 3859-75.

Turley, L.W. and Milliman, R.E. (2000). Atmospheric effects on shopping behavior: A review of the experimental evidence. Journal of Business Research, 49(2), 193-211.

van der Schyff, D. and Schiavio, A. (2017). The future of musical emotions. Frontiers in Psychology, 8(988), 1-5.

van der Schyff, D., Schiavio, A., and Elliott, D.J. (2016). Critical ontology for an enactive music pedagogy. Action, Criticism, and Theory for Music Education, 15(5), 81-121.

Vermetten, E. and Bremner, J.D. (2003). Olfaction as a traumatic reminder in posttraumatic stress disorder: Case reports and review. The Journal of Clinical Psychiatry, 64(2), 202-7.

Vold, K. (2015). The parity argument for extended consciousness. Journal of Consciousness Studies, 22(3-4), 16-33.

Wallace, W.T. (1994). Memory for music: Effect of melody on recall of text. Journal of Experimental Psychology. Learning, Memory, and Cognition, 20(6), 1471-85.

Ward, D. (2012). Enjoying the spread: Conscious externalism reconsidered. Mind, 121(483), 731-51.

Windsor, W.L. and de Bézenac, C. (2012). Music and affordances. Musicae Scientiae, 16(1), 102-20.

Witek, M.A.G., Clarke, E.F., Wallentin, M., Kringelbach, M.L., and Vuust, P. (2014). Syncopation, body-movement and pleasure in groove music. PLoS One, 9(4), e94446.

Witvliet, C.V. and Vrana, S.R. (1996). The emotional impact of instrumental music on affect ratings, facial EMG, autonomic response, and the startle reflex: Effects of valence and arousal. Psychophysiology Supplement, 91, 88-91.

Wynn, M. (2004). Musical affects and the life of faith. Faith and Philosophy: Journal of the Society of Christian Philosophers, 21(1), 25-44.

\section{Notes:}

( $\left.{ }^{1}\right)$ Even these solitary forms of listening, however, are not truly 'worldless'. They occur in specific listening contexts, and involve artefacts, practices, associations, and preferences that reflect the listener's sociocultural ecology, and shape how they perceive and interpret the music (Clarke 2005: 126-55). 
$\left({ }^{2}\right)$ Of course, this may not equally be the case for all forms of music-such as noise music or avant-garde electronic music consisting of pure tones, electronic signals (feedback, distortion, tape hiss), or music with a minimal or randomly generated structure (e.g. a few irregular blips or industrial sounds punctuated by long stretches of silence). Alternatively, non-musical field recordings of natural or artificial landscapes may, like music, also become present to consciousness as rich sounding environments inviting further exploration. Part of the philosophical curiosity of music and sound comes from trying to account for these sorts of challenging cases.

$\left({ }^{3}\right)$ These considerations also help clarify why amusiacs-who show a deficiency processing pitch variation despite normal speech perception and intact sense of rhythm-tend to describe music as unpleasant, unstructured noise (McDonald and Stewart 2008; Sacks 2007). There is evidence that amusia involves, among other things, an inability to represent space (Cupchik et al. 2001; Douglas and Bilkey 2007; Särkämö et al. 2009). When the spatial content of music is no longer present to consciousness, music loses its distinctively musical character. For a different view of amusia and space, however, see Tillmann et al. (2010).

$\left({ }^{4}\right)$ Of course, we also 'resonate', in deep and powerful ways, with input from other perceptual modalities, too. There is evidence that smells, for example, trigger intense emotionally-tinged autobiographical and episodic memories (Herz et al. 2004; Saive et al. 2014), such as the negative emotions experienced by those suffering from posttraumatic stress syndrome (PTSD) (Vermetten and Bremner 2003). However, the multi-level (i.e., neurophysiological, behavioural, and phenomenological) entrainment responses that music elicits mean that we are drawn up into musical worlds in a manner distinct from, say, the olfactory environments we inhabit. I invite the reader sceptical of this point to imagine being locked in a room with an unpleasant odour continuously pumped in via a vent versus being in that same room while music is continuously played at a punishingly high volume. Neither experience would be pleasant. But my intuition is that the former would be the more bearable of the two scenarios, in part because we can actively modulate our exposure to smells (i.e., how much we let inside of us) to a greater degree than we can music.

\section{Access brought to you by:}

